\section{Effects of deprivation and prefeeding on variable interval responding*}

\author{
ROBERT W. POWELL \\ University of South Florida, Tampa, Fla. 33620
}

Three pigeons with long operant conditioning histories were studied under a variable interval schedule as deprivation was varied. Periods of food deprivation up to $72 \mathrm{~h}$ and prefeeding up to $20 \mathrm{~g}$ of food had little effect upon responding. One pigeon did show a significant decrease in responding following a $10 \%$ increase in body weight. These findings indicate that variable interval responding in pigeons can become relatively insensitive to changes in deprivation.

While innumerable studies have shown that changes in deprivation (drive) have potent direct effects upon instrumental responding, results pertaining to behavior under variable interval (VI) schedules have been somewhat equivocal. Ferster \& Skinner (1957) varied body weight unsystematically in four pigeons. Two of the birds had generally higher response rates at lower weights, but two birds showed no consistent relationship between body weight and rate of response. These authors also found that prefeeding up to $80 \mathrm{~g}$ of food immediately prior to the session had no effect on the responding of one pigeon, while the second bird showed a decrease in rate only at the maximum amount fed.

Clark (1958) found that VI responding in rats increased as deprivation time increased from 1 to $23 \mathrm{~h}$. The relationship between response rate and deprivation time can be characterized as a negatively accelerated increasing function. In a study of discrimination, Dinsmoor (1952) found a linear increase in responding under a VI schedule as body weight decreased from satiation to $75 \%$ of the animal's free-feeding weight. Both of these studies employed rats and reported only group data. Thus, the extent to which the group curves are representative of individual performance cannot be specified.

In a recent experiment which involved the effects of deprivation upon a successive visual discrimination, Powell (1971) found that only one of the four pigeons showed a consistent relationship between deprivation level and rate of VI responding. Each pigeon was studied under two deprivation procedures: (1) systematic changes in body weight, and (2) 24,48 , or $72 \mathrm{~h}$

\footnotetext{
* Reprints may be obtained from the author, Department of Behavioral Science. University of South Florida, Tampa, Fla. 33620 .
}

of food deprivation prior to the session.

The present experiment was undertaken to study in detail the effects of deprivation upon VI responding in pigeons. A baseline procedure was used in which stable responding was established and then repeated measurements were made at several deprivation levels. Relatively brief sessions were employed in order to minimize satiation effects within the session.

\section{SUBJECTS}

Three adult male White Carneaux pigeons were used. Bird 29 had a history of training under variable ratio (VR) and VI schedules, while Birds 33 and 45 had been trained under fixed ratio (FR), VR, and VI schedules. Water and grit were available at all times in the home cages.

\section{APPARATUS}

A Lehigh Valley pigeon test chamber, Model 1519C, was employed. A minimum force of $15 \mathrm{~g}$ $(0.147 \mathrm{~N})$ was required to operate a microswitch attached to the response key. Mixed grain was used for reinforcement. The reinforcement time was 2.5 sec for each bird. During reinforcement, the key light was turned off. All scheduling was accomplished by standard relay circuitry. Data were recorded by digital counters and a Gerbrands cumulative recorder.

\section{PROCEDURE}

Each bird was trained under a VI 60-sec schedule until performance stabilized. The stability criterion was variation in the response rate of $\pm 10 \%$ or less of the mean rate over 10 consecutive sessions. Sessions were $50 \mathrm{~min}$ in duration throughout the experiment. Response rate was calculated by dividing total responses by total time less reinforcement time. Body weights during training were approximately $78 \%$ (Bird 33), 79\% (Bird 29), and $86 \%$ (Bird 45) of each a nimal's free-feeding weight. The numbers of training sessions, prior to changes in deprivation, were as follows: Bird 29 (24), Bird 33 (21), Bird $45(23)$.

Changes in deprivation were accomplished through the following procedures according to the sequence indicated.

Hours of Food Deprivation

Food was withheld for 24,48 , or $72 \mathrm{~h}$ prior to the experimental sessions. The sequence of deprivation periods was generally $72,24,48,24 \mathrm{~h}$. The birds were given supplemental feeding after each session in order to keep body weight at the same level as during training.

\section{Prefeeding}

The birds were fed 0,10 , or $20 \mathrm{~g}$ of mixed grain $1 \mathrm{~h}$ prior to the session. The prefeeding sequence varied unsystematically. Each bird was studied for a series of sessions at two different weight levels. Weight was increased after the first experimental series by supplemental feeding over 5 to 7 days, and then the second series started. The mean percent body weights, which were determined prior to prefeeding, were as follows: Bird 29 ( $84 \%$ and $94 \%$ ), Bird $33(84 \%$ and $93 \%)$, Bird $45(88 \%$ and $96 \%)$.

RESULTS AND DISCUSSION

The length of the food deprivation period had no consistent effect upon VI responding. Figure 1 shows that each pigeon maintained a fairly consistent rate of responding across deprivation conditions. A Friedman two-way analysis of variance showed that the difference in response rates as a function of hours of deprivation was not statistically significant $(p<.94)$. Inter-S reliability was very high, with

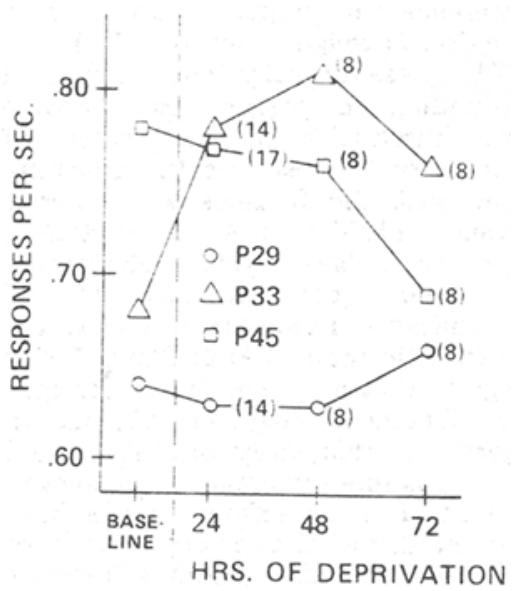

Fig. 1. Mean VI response rates for each bird as a function of hours of deprivation. The numbers in parentheses indicate the number of sessions upon which the corresponding data points are based. The data points corresponding to "baseline" on the abscissa represent the final 10 sessions prior to changes in deprivation. 
the maximum difference in rates being only .18 responses/sec $\quad(648$ responses/h). The largest and smallest hourly rates were 2,916 (P33) and 2,268 (P29) responses.

Prefeeding 0,10 , or $20 \mathrm{~g}$ had no obvious effect upon responding. Figure 2 shows that response rates were stable across prefeeding amounts. Friedman analyses of variance showed that there was no difference in response rates at either the low weight level $(p<.94)$ or the high weight level $(p<.94)$ as a function of prefeeding amount. Individual Kruskal-Wallis analyses were used to compare differences in response rates at the two weight levels for each prefeeding amount. Only Bird 45 showed differences in response rate at the two weight levels. The probabilities indicated by the statistical test $(\mathrm{H})$ were as follows: Bird 29, $0 \mathrm{~g}(.50)$, $10 \mathrm{~g} \mathrm{(.10),} 20 \mathrm{~g} \mathrm{(.50);} \mathrm{Bird} \mathrm{33,} 0 \mathrm{~g}$, (.80), $10 \mathrm{~g}(.90), 20 \mathrm{~g}(.50)$; Bird 45, $0 \mathrm{~g}(.02), 10 \mathrm{~g}(.01), 20 \mathrm{~g}(.01)$.

Each pigeon responded at nearly the same rate throughout the entire experiment, as shown by a comparison of responding during the final 10 sessions prior to changes in deprivation time, with the sessions at the two weight levels during prefeeding when no food was given prior to the session. Thus, deprivation conditions were essentially the same except for the animal's body weight. The response rates per second as a function of body weight were as follows: Bird $29,(79 \%)$ $.64,(84 \%) .60,(94 \%) .58$; Bird 33, (78\%) $.68,(84 \%) .75,(93 \%) .76$ Bird $45,(86 \%) .78,(88 \%) .77,(96 \%)$ 67. A Friedman analysis of variance showed that there was no overall difference in response rates as a function of weight level ( $p<.53$ ).

The present results indicate that VI responding in pigeons can become quite insensitive to the effects of deprivation. These results generally agree with the findings of Ferster \& Skinner (1957), who also studied pigeons. The direct relationship observed between rate of VI responding and amount of deprivation in rats (Dinsmoor, 1952; Clark, 1959) suggests that a species difference may exist between rats and pigeons in regard to this function. There are other possible explanations, however. In each of the experiments which have been cited, the pigeons appear to have had more extended training histories than the rats. It may be that sensitivity to the influence of certain independent variables decreases as exposure to a particular schedule of reinforcement increases.

Several studies have shown that both rats and pigeons perform

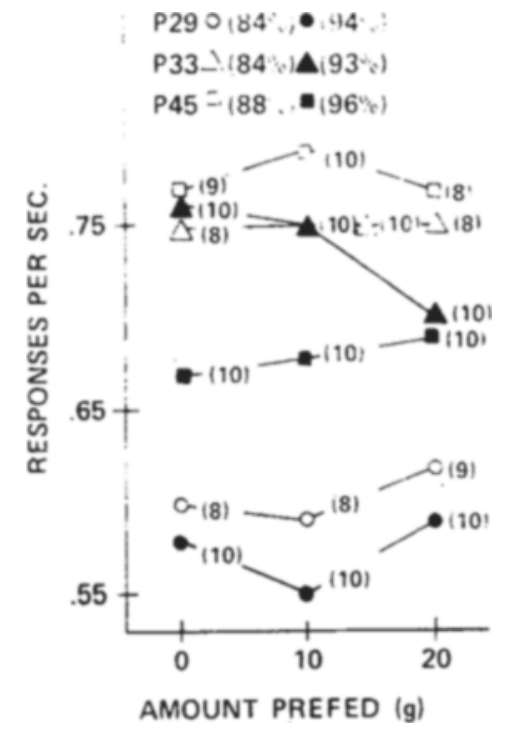

Fig. 2. Mean VI response rates at the two weight levels for each bird as a function of prefeeding amount. Open and closed symbols represent the lower and higher weights, respectively. The numbers in parentheses indicate the number of sessions upon which the corresponding data points are based.

instrumental responses in order to obtain food, even though identical food is freely available within the experimental chamber (Jensen, 1963; Neuringer, 1969). When a specified number of responses was required to obtain food (FR schedule), both rats and pigeons ate the freely available food and made few responses, when the ratio requirement was 10 or larger (Carder \& Berkowitz, 1970; Neuringer, 1970). However, with a VI 1-min schedule in effect, three pigeons responded on the average of 26 to 64 times per reinforcement for 45 reinforcements per session, with $240 \mathrm{~g}$ of grain freely available in the test chamber (Neuringer, 1970). They also ate large amounts of the free food. Thus, VI responding is very persistent, even when food can be obtained without responding.

Several experiments have shown that the effect of a variable upon responding depends, to a large extent, upon how the response affects the rate of delivery of the variable. Rachlin (1967) observed that shock affected behavior most drastically when behavior, in turn, affected the rate of shock. Similarly, Neuringer (1967) found that the effect of reinforcement magnitude partly depends upon the extent to which responding influences the amount of reinforcement. Rate of reinforcement under VI schedules changes very little with substantial changes in response rate, as long as responding is fairly stable. It has been demonstrated that VI responding does increase when rate of reinforcement increases (Catania \& Reynolds, 1968). Also, it has been observed that responding under a VI schedule is more resistant to suppression by punishment than responding under a variable-ratio (VR) schedule. The effect was attributed to the slight decrease in reinforcement rate that occurs as VI responding decreases, whereas reinforcement rate under VR schedules decreases in direct proportion to decreases in response rate (Powell, 1970). Each of the pigeons in the present experiment had a very stable response pattern, so rate of reinforcement was nearly constant. As a whole, these findings suggest that variable-interval behavior may be difficult to alter through deprivation or other independent variables because changes in response rate have negligible effects upon rate of reinforcement.

\section{REFERENCES}

CARDER, B., \& BERKOWITZ, K. Rat's preference for earned in comparison with free food. Science, 1970, 167. $1273-1274$.

CATANIA, A, C. \& REYNOLDS, G. S. A quantitative analysis of the responding maintained by interval schedules of reinforcement. Journal of the Experimental Analysis of Behavior, 1968, 11, 327-383.

CLARK, F.C. The effect of deprivation and frequency of reinforcement on variable-interval responding. Journal of the Experimental Analysis of Behavior, 1958, 1, 221-228.

DINSMOOR, J. A. The effect of hunger on discriminated responding. Journal of Abnormal \& Social Psychology, 1952, 47. 67-72.

FERSTER, C. B., \& SKINNER, B. F. Schedules of reinforcement. New York: Appleton-Century-Crofts, 1957.

JENSEN, G. D. Preference for bar pressing over "free loading" as a function of number of rewarded presses. Journal of Experimental Psychology, 1963, 65, $451-454$.

NEURINGER, A. J. Effects of reinforcement magnitude on choice and rate of responding. Joumal of the Experimental Analy sis of Behavior, 1967, $10,417.424$

NEURINGER, A. J. Animals respond for food in the presence of free food. Science, $1969,166,399-401$

NEURINGER, A. J. Many responses per food reward with free food present. Science, 1970, 169, 503-504.

POWELL, $R$. W. The effect of punishment shock intensity upon responding under multiple schedules. Journal of the Experimental Analysis of Behavior, 1970 , 14, 201-211

POWELL, R. W, Evidence of interaction between deprivation effects and stimulus control. Journal of the Experimental Analysis of Behavior, 1971, 16, 95-104.

RACHLIN, H. The effect of shock intensity on concurrent and single-key responding in concurrent chain schedules. Journal of the Experimental Analysis of Behavior, $1967,10,87-93$. 